\title{
The Impact of Career Risk on Productivity in The Construction Sector of Libya:A pilot study
}

\author{
Juma Aseed Mohamed Buajela, Sadun Naser Yassin Alheety \\ Department of Management, Al-Madina International University, Kualalumpur-Malaysia
}

\begin{abstract}
The Construction sector impacts virtually all aspects of our lives - home, leisure, school, and workplace. The construction is an integral part of creating and maintaining an acceptable standard of living in Libya, yet the Construction sector faces extraordinary health and safety challenges. Construction employees are paying dearly for the opportunity to earn a living. These challenges and the means to meet these challenges need attention. Libya is being one of the developing countries and its different Construction sectors are substantial components of the economy. Although the Libyan construction sector rapidly grew and developed rapidly, they still face challenges that affect their competitiveness. The purpose of the current study is to evaluate Career Risk on Productivity in The Construction Sector of Libya as A pilot study. The context of this study was the construction industries in Libya. A total of $\mathbf{4 0}$ responses from employees were drawn from construction firms in Libya. This was achieved using a probability type sampling in which stratified random sampling was applied. The quantitative method has been selected using the empirical study with a designed questionnaire comprised of 38 questions and involved 40 respondents comprising of the Administrative, Construction worker, and Supervisors. The data analysis is divided into three phases: initial data analysis - the pilot study, statistical analysis to develop a model and to test the study hypothesis. All stages of data analysis use the method of Structural equation modelling. The results showed that Career Risk is not significantly at the level of 0.05 , the p-value is .719 which is greater than .05 . Therefore, a hypothesis which assumes Career Risk has a positive impact on Organizational Productivity was rejected. The most implication for this study, Theoretically, the main drive of this investigation was to evaluate Career Risk on Productivity in The Construction Sector of Libya. Human resource management literature shows a link between Career Risk and organizational productivity. One of the most important recommendations of the study since Career Risk was an international notion besides requires to be considered for further investigations throughout a great amount of broader environmental well as researched within the scope of a greater and more comprehensive populace, it is recommended to future researchers to gather data from other research contexts, and to some other industries so that hidden variables can be identified as well as a comparative analysis can be carried out.
\end{abstract}

Keywords:Career Risk; Productivity; Construction Sector.

\section{INTRODUCTION}

$\mathrm{T}$ he construction industry has an influence on nearly every part of our lives-home, entertainment, school and work. The sector is integral to the development and maintenance of an appropriate standard of living in Libya, but the construction sector faces exceptional challenges. Building workers' pay a high price for the chance to make a living.
These problems and the means to overcome them are critical (Tatar, 2020).Libya is one of the developing countries and its numerous construction sectors are essential economic components. Even if Libyan industries have been rapidly growing, they still face competitive challenges.

The key issues facing Libyan companies are Career Risk for the workplace, in addition to employee protection status in the working climate, face the challenges of organizational and environmental well-being. The incidence of workplace injuries and non-conduct work conditions are the factors that affect the facts. Most workers in the sector think "producing is ahead of protection," making it one of the leading causes of injury. The attitudes, methods, and activities that can have a significant and enduring effect on learners in the teacher model of these programmes. Systems must be built that provide instructors with current and industrial tools to create a strong security education culture within their programs (Tatar, 2020).

The trends related to the social responsibility of the international organization were defined to standardize the social responsibility of the company whose decisions and activities affect society. There was clear and moral conducting which underwrites to maintainable improvement in the aspects of health and well-being towards that community; The interest is in line with the law and adheres to codes of conduct throughout the world; it has been incorporated into the company and applied in its affiliations (Judge et al., 2017). "

Monitoring is considered as a single utmost imperative characteristic of organizational environmental healthiness, prevention of workplace hazards, and employee safety, which helps to understand organizational health protection trends. The main objective of monitoring is to discover new ways of prevention, to identify the magnitude and spread of the problem, to identify trends, priorities, and to disseminate results that facilitate choices that improve regulatory environmental health and protect neighboring areas of work. Three levels were identified: risk, exposure, and outcomes (Karatepe\&Avci, 2017). These levels have a correlation with the degree of injury and prevention of infection: by three things. The ability to know the risks before they occur that harm employees and this is considered the first preventive measure. figuring out what people are uncovered to offer a risk to undergo an injury, sicknesses, and fatal danger earlier than its impacts grow to be extra cutting-edge (in other words alternative avoidance) (Judge et al., 2017). 
Career risk and Productivity were studied by the researcher in this study as components that belong to the establishment's community accountability towards organizational environmental health and employee workplace safety. Organizational productiveness could be described as enactment scales, that incorporate together employee competence besides efficacy (Olu \& Majekodunmi, 2020).

Consequently, standards of organizational productiveness in regards to the present research were efficacy also competence. Hence effectiveness and efficiency are applied in the present research to determine the impact employee career attitudes via career risk possess within productiveness related to an organization.

The objective for this study to examine the impact of the Career Commitment on Organizational Productivity of Construction companies in Libya. The study examined the research question: Is there an impact of the Career Risk on Organizational Productivity of Construction companies in Libya?The study also developed thehypothesis: Career Risk (CR) has a positive significant relationship with Organizational Productivity (OP).

\section{LITERATURE REVIEW}

\subsection{Career Risk}

Theoretical modeling of risk behavior has been given crucial and effective implications by the risk propensity. There is feasible understanding have been obtained about the underlying motivations and the truth behind the individual's choices to engage in risky behavior. Organizationally, risk management programs can substantially, contribute to a better understanding of risk behavior. (Nicholson et al, 2005)

The literature reviews are in related with to risk propensity includes three topics. Firstly, topic concerns the theories of the expected utility, which is the theory of probability (Herrero et al., 2016). For instance, the asymmetric risk around a reference point is suggested by the prospect theory. The people consider themselves to be in the field of gain or risk, when they will be at the field of risk because of seeking in to be in the field of loss. The several research studies in risk and risk preferences have been stimulated by the prospect theory. risks at the individual level are one of the theoretical hypotheses, which hypotheses are relatively inconsistent in the examined cases - someone may face dangers in certain conditions, so he has to avoid risks in other circumstances. The prompts of behavioral changing can be easy as the data's semantic display, for example, in both cases if the result of examining displayed a loss or gain. Also, framing is considered a strong phenomenon, especially when the reference points and outcomes are manipulated which is founded by a meta-analysis of the effects of framing (Franco \&D'Angelo, 2011).

Many framing-related studies take into account aggregated data which is considered better than individual data. The issue of methodology has a serious impact on understanding the risks. Factors that may affect risk behavior and to frame effects have considered and mentioned in detail in some research that takes into account differences factors of the individual which can affect risk. it seems that the person is the strongest factor of the main factors among the psychological factors which effects on risky behavior. Phipps et al. (2013) suggested that the apparently contradictory results with the theory the risk in cases of gain and aversion to risk in losing in reference to individual differences in conceptions about what is considered an opportunity and threat (Mertens, 2008). The propensity of risk can be more attributes of the personal than his status. This area, the sensation has been found by searching to be of particular importance. The writer Zuckerman produced the study (Mishra \&Lalmer, 2011), many types of research have ensured, due to it is very consistent is considered a very important indicator of diverse types of risk, which the compulsive gambling and participation activities are included within the high-risk situation (Mishra \& Lalomir, 2011).

The related individual method has been considered in the risk propensity in terms of various and individual measures within risks. in an earlier research, there is an example of this work is Harrison et al (2005), also many recent studies have ensured the same approach (e.g., Hanoch et al., 2006). There is a big attention on the inter scores in correlation have been focused by the empirical works -taking in different decision areas in reference to measurements the rate of risk.

The results have shown that typically there are the weak affiliations between different measures of risk, there is a suggestion which shows that generalized trends for avoiding risk haven't been got by the most people.

In reference to that, this type of results does not prevent the possibility of a strong intra-individual gathering of different measures of risk which is shown by research about the management's decision-making by Blais\& Weber (2006).

A few people showed harmonic responses in different measures of risk- which are taking. The researchers categorized these as the seekers of consistent risk and averters. (Lauriola\& Levi (2001) in their second work and Weber et al, (2002) produced a noticeable improvement in this area.

Understanding the degree of danger in a situation can range is mentioned by authors and thus in reference to the characteristics of the situation, attitude to perceived risk and an enormous portion in their sample. The degree to which people find perceived risk attractive has remained stable across situations. This work is situational and individual approaches of combination and described as a part of the third way of literature which trended to risk.

\subsection{Organizational Productivity}

Organizational productivity had brought a lot of interest in the latest years. Organizational productivity is a simple purpose of behind administration these days' businesses condition. That is 
so because of the reality if the efficiency of an organization is superior to that of its rivals, that association endures better in light of the fact that higher profitability will bring about sophisticated benefits, in addition, an additional employment possibility (Tchapchet, 2013).

Performance means organizational productivity metrics. Effectiveness means achieving organizational goals, which leads to the raising of workers' satisfaction levels, and productivity talks about to reducing the charge of assets and success in achieving the goal of the organization. Phipps et al., (2013) define the Organizational productivity is defined as the relationship between the outputs generated from the production system and the inputs that result in the creation of the output. For this reason, productivity is defined as the efficient use of organizational resources. Organizational effectiveness is to be aware of the company's ability to achieve the results sought by the organization. Which has a critical role in accelerating organizational improvement (Wearing \& Neil, 2009).

according to Okoye\&Ezejiofor (2013), a common and critical topic is the enhancement of organizational efficiency. Each private or public corporation should strive to increase its efficiency and make better use of its capital to fulfil its customers ' needs and therefore remain in the market. improving productivity is an issue that has been substantial and will keep on being substantial. All organizations whether private or open should try to improve their profitability and best use their assets so one can address the issues of their clients, and hence remain in the market.

Corporate productivity is a mixture of the reliability of the organization's efficiency and effectiveness in calculating and inputting the degree of operational results. This is the relation of outputs to any criterion or goal, as is the monthly production performance of the processing unit separated into the number of hours used to produce output.

An organization can utilize its workforce to be increasingly compelling. individuals are vital to organization execution and efficiency. while supervisors and workers are supported and have the correct abilities, execution goals are accomplished and are routinely surpassed. These organizations are typically increasingly proficient, amazing and beneficial when contrasted with organizations that don't enable workers to associate and take part in basic leadership.

\subsection{Theoretical Review}

Maslow said if people are nurtured in places where their needs are not met, that it is unlikely that they will work healthily in comparison to people whose needs are fulfilled in the environment. Research which challenges the theory of Maslow has supported the distinction between basic needs and growth needs but has shown not all are able to satisfy their growth wishes in the workplace.

Based on findings from past studies, a company's managers at or above strategic levels can satisfy both its growth and lack of requirements. In contrast, operational or functional individuals can meet their basic needs at work in particular.

According to Nduro (2012), the scientist continues to differ and does not completely share Maslow's views on the theory as a whole, he said workers have various needs because of the complexity of human life. Furthermore, he emphasized that human needs are divided into groups forming the hierarchy, and it is not right for science to show that it is difficult to make human nature versatile to do things. This makes it extremely difficult for them to measure static instruments and to arrange their needs into a defined hierarchy. Thirdly, once experienced, he realized that a need is not a need anymore. The argument is that the needs of staff cannot be easily addressed because the pilot study showed that the needs of employees differed from the ones that overlapped at a time.

Maslow's theory is still very relevant and applicable in current organizational settings although one of the earliest advocated motivation theories. It was able to identify, despite its shortcomings, those individual-specific necessities and their consequences on the levels of performance or productivity of an individual in an organization. Managers should therefore try to understand the needs of employees and offer appropriate motivation that is tailored to meet or satisfy these requirements. The organization should consider employees as an organization's own backbone, in order to achieve a high degree of productivity by members of the workforce. Therefore, Maslow's theory argues that first of all workers ' needs should be taken into account to ensure that workers continue to be very productive and to strive to achieve continued growth, stability and success.

\section{METHODOLOGY}

\subsection{Research Philosophy}

This thesis took a conceptual approach to positivism to define questions from analysis - an approach that evaluates the validity and significance of knowledge collected after data collection through a robust and programmed approach. This theory ensures that the truth is shed in an objective manner, where quantitative precision and the acquisition of facts that explain truth without any biases or intervention are the priority (Babbie and Rubin, 2010).

It is difficult for metaphysics, information theory, theory, and technique during research to be isolated, according to HesseBiber et al. (2006). In order to settle on a research methodology to be followed which will satisfy a group of fundamental convictions (frame) relevant to reality (Guba and Lincoln 1994), the scientist must then assess the relationships between adequate frameworks \& methodologies.

The most effectively applied theoretical models in the literature include phenomenal, interpretive/systemic, and quantitative research related to positioning (Collis and Hussey, 2013). The findings of this analysis include qualitative research. The underlying debate that confirms the alternate discrepancies in study methods focuses on divergent 
social reality assumptions. For example, the quantitative analysis takes into account reality, according to Lawrence \&Suddaby (2006).

Therefore, the present analysis uses the survey questionnaire for the primary data collection to establish a quantitative approach. In exploratory, descriptive and informal research supporting quantitative design the majority of studies in the fields of the industry are classified (Hart, 2001). More research studies in the business sector are often known as research studies on the basis of the nature of the subject area (Crossan, 2003) which are exploratory, descriptive, or confirmatory.

This work proposes to investigate factors that may affect Construction companies' adoption to apply health and occupational safety. Moreover, it extends our knowledge of the factors affecting health and occupational safety applied by Construction companies in Lybia. Hence, this research undertakes an explanatory study with a quantitative approach.

\subsection{Research Approach}

The selection of appropriate approaches and methods assumes critical importance when conducting research (Galliers, 1992). A review of prior studies in prior Health and Occupational Safety application research helps to identify the most appropriate approach to carry out the research.

Myers (1997) reported. In natural sciences, quantitative analysis techniques for natural phenomena were originally developed. Straub and others (2004) have described quantitative (positivist) research as a technique that enables IS researchers to address questions about human and computer interactions. The focus of quantitative studies is on the testing and generalization of hypotheses for a broader population (Balakrishnan et al. 2007). QM examples include surveys, laboratory studies, structured (e.g., econometric, econometric) methods, and computational methods like mathematical modelling. They conclude that the most common approach to research is the quantitative approach today.

With regard to the type of research methodology, some researchers found that a cross-section survey is the most commonly used in adoption research. The next most popular methods are the case study, and interviews. This view is confirmed by Chen et al. (2013). They found that $74.3 \%$ of the adoption research was based on the survey method while case study and interviews accounted for $4.7 \%$ and $4.4 \%$ respectively. Mohamad and Ismail et al. (2009) argue that because the survey method enables researchers to generalize their findings, it is more popular among them.

It can be seen from the above analysis that the survey approach dominates management adoption research methodologies. It provides snapshots of specific practices or behaviour in a specific time from which inferences may be made (Zeng\& Lin, 2007). It is realistic and helps make proper generalizations. Additionally, it enables the researcher to focus on a specific problem, to pursue a rigorous method, and to generate valid conclusions (Sekaran\&Bougie, 2003). Pinsonneault and Kraemer (1993) emphasize that the survey approach is most appropriate when the dependent and independent variables are well-defined and a conceptual model of the expected relationships exists. This study has a well-defined dependent variable and there is clear causality between research variables and is supported by a theoretical basis. This study will adopt the survey approach to investigate and examine the research framework.

\subsection{Research Design}

Research design has simply been described as the research methods and frameworks determined by the researcher himself to comply with the data collection and analysis norm (Wearing \& Neil, 2009). In any search, search design is essential. This step includes decision-making about the target, location, form, processing, control, and analysis level (Sekaran, 2003).

A crucial step that helps draw up a checklist that can direct researchers' activities and processes in achieving research objectives and in testing the validity of assumptions.

Due to its nature, this study will use structural equation (SEM) to carry out the structure and contents authority of all variables with Confirmation Factor Analysis. The next step is to perform descriptive research to obtain a profile of the respondent, measure population variables frequencies, and validate the norm, average variables.

This allows the investigator to document each building's current condition. Furthermore, the impact of the intermediate variables as defined in the theoretical context has been explored by SEM. The research design of the study is considered to be the most developed one because it helped to create the correlation between the independent variables and the dependent variable.

\subsection{Population and Sampling}

\subsubsection{Population}

According to Berg et al. (2011), the population is any group of individuals possessing one or more common properties of interest to the scholar called the population. The construction industries were the main focus of this research because they formed a larger percentage of industries in Libya. The target population of this research is the field staff of the construction companies in Libya. The field employees would be surveyed. The reason for this is that these are the group of employees who are directly involved in activities that directly relates to the hazards and principles of health and safety. This is in agreement with Zohar (2011).

Also, in line with this target population selected, Mearns et al (2001) assert that the field employees in the construction industry form the highest probability of employees in which safety Behaviours are most influenced. This is due to the following three reasons: the presence of risk; beliefs about the gravity of the consequences; and perceived control over the 
risks. These categories of employees are therefore most eligible for occupational safety training programs toward workplace safety. They will be surveyed because they have the requisite knowledge, experience, and expertise to take part in the survey (Saunders et al., 2009). It is believed that these groups of employees possess the requisite knowledge to take part in this survey and provide responses to the objective achievement of this study. Sixty-three (63) construction companies will be surveyed. The construction companies were selected by means of a systematic stratification sampling method.

\subsubsection{Sampling}

The objective of the quantitative approach to developing some descriptive statistics of the vital measures for the intention of generalizing (Cavana et al., 2001). The sample size was selected to allow for representativeness of the population; that is probability sampling. Probability sampling is appropriate for generalization and is built up of mere random sampling and complex probability sampling (Cavana et al., 2001).

This study adopted a proportionate stratified random sampling method. This involved separating the population into sub-groups and then randomly drawing a sample from each group (Gay et al., 2006). Stratification is an efficient research sampling design because it ensures that the resulting sample is distributed in the same way as the population in terms of the stratifying criterion (Hair, 2010). A systematic random sampling method was utilized in this field, to enable it to generalize to the population (Bryman\& Bell, 2015). Hair (2010) recommend selecting a random sample in which each person in the population has an equal probability of being chosen.

Leedy and Ormrod (2005) also emphasize that in selecting a random sample, the researcher can take for granted that the characteristics of the sample approximate the characteristics of the population.

By being large enough large to determine the characteristics and the integrity of the population, the sample size should be adaptable to the investigation. Samples are stated to be large enough to estimate the population's characteristics satisfactorily so as to have practical solutions.

Felt et al. (1998) reported that the sample size should not be less than 200, in particular in the field of science. This is tangible since it could be not running or causing an error by using SEM when the sample size reduces for each variable or parameter. The ratio of cases to indicator numbers/items is however 20:1.

In reference to Krejcie and Morgan (1970), a population size of 75 corresponds to a sample size of 63 companies. 40 respondents were being surveyed as a sampling for pilot study.

\section{RESULTS AND DISCUSSION}

\subsection{Data Screening}

The field survey involved the use of a self-administered questionnaire survey, that was administered directly to the research populations. The questionnaires were divided into 3 segments: A, B, and C. Section A covers on the demographics (6 items) of the respondents. The options were anchored on the nominal and interval scales and the data type was categorical. Section B covers the measurement of "Career Risk' (7 items). Section C covers the measurement of Organizational Productivity (10 items).

The section $\mathrm{B}$, and $\mathrm{C}$ contained responses that were anchored on the Likert scale, and the data type was continuous. There was a total of 17 measurable questionnaire items in this section which were related to the research variables. In total, there were 23 questionnaire items. 6 from section $\mathrm{A}$, and 17 from sections $\mathrm{B}$, and $\mathrm{C}$.

The data gathered from the survey participants related to these questionnaire items were coded by means of characters and numbers and manually entered into SPSS version 26.0 for the screening procedure.

The screening of the survey data was necessary in order to detect incorrectly filled or incompletely filled questionnaires. This procedure was facilitated by the SPSS software by means of the frequency distribution of the data.

\subsection{Descriptive Analysis of the RespondentsBackground}

The current section covers the demographic data concerning the respondents as obtained from the pilot study carried out. As can be seen, Table 1 exhibits the details of the variables of Gender, Marital Status, Age, Education, Job Position, and Experience, as provided by the respondents.

\begin{tabular}{|c|c|c|c|}
\hline Variable & Category & Frequency & $\%$ \\
\hline \multirow{2}{*}{ Gender } & Male & 36 & $90 \%$ \\
\hline & Female & 4 & $10 \%$ \\
\hline \multirow{2}{*}{ Marital status } & Single & 12 & $30 \%$ \\
\hline & Married & 28 & $70 \%$ \\
\hline \multirow{5}{*}{ Age } & Less than 20 & 1 & $3 \%$ \\
\hline & $21-30$ & 8 & $20 \%$ \\
\hline & $31-40$ & 15 & $37 \%$ \\
\hline & $41-50$ & 11 & $27 \%$ \\
\hline & More than 50 & 5 & $13 \%$ \\
\hline \multirow{4}{*}{ Education } & Secondary school & 16 & $40 \%$ \\
\hline & Diploma & 9 & $22 \%$ \\
\hline & Bachelor's & 14 & $35 \%$ \\
\hline & Post graduate & 1 & $3 \%$ \\
\hline \multirow{3}{*}{ Job position } & Administrative & 4 & $10 \%$ \\
\hline & Construction worker & 27 & $68 \%$ \\
\hline & Supervisor & 9 & $22 \%$ \\
\hline \multirow{4}{*}{ Experience } & Less than 2 years & 8 & $20 \%$ \\
\hline & $2-5$ years & 19 & $48 \%$ \\
\hline & 6-11 years & 7 & $17 \%$ \\
\hline & More than 11 years & 6 & $15 \%$ \\
\hline
\end{tabular}


The pilot study outcomes as highlighted in Table above demonstrate that among the 40 selected respondents, the majority were male $(\mathrm{n}=36,90 \%)$ whereas the rest were female $(\mathrm{n}=4,10 \%)$. The respondents were mostly aged between 31-40 years $(\mathrm{n}=15,37 \%)$ whereas those aged $41-50$ years were the next highest in proportion where $\mathrm{n}=11$ which is equivalent to $27 \%$. The outcomes obtained from the pilot study also indicate the level of education of the participants. Here, it appears that most respondents held Secondary school qualifications $(\mathrm{n}=16,40 \%)$. This is followed by those with a Bachelor's degree $(n=14,35 \%)$. Results also showed that the majority have between $2-5$ years' experience $(\mathrm{n}=19,48 \%)$ followed by those with less than 2 years of experience $(n=8$, $20 \%$ ).

\subsection{Pilot Study Reliability}

Table 2 shows the typical assessment of the estimation model of the Strategic Human Resources Practices (Two variables). Chua (2013) stated that the limits for the type of information, skewness and kurtosis should be within the range of- 1.96 to + 1.96. Kline (2005) argued that factors with higher skewness estimates than 3.0 appear to be highly skewed, and the moderate general guideline is that all the accounts suggest that total estimations of the kurtosis record are more prominent than 10.0. The consequences of the factual examinations indicated the similarity of the information to the characteristic.

As the scientists have indicated, conducting a pilot study would help the specialist from a wide range of points of view before the final gathering of information. It would help to change the investigation if it were strategic. In this way, the pilot considers it appropriate to assess the feasibility of a fullscale approach, to establish whether the test case and procedures are powerful and to distinguish the strategic issues that may arise from the use of the proposed techniques.

Thus, the pilot-directed scientist is thinking about the arrangement of members chosen from the population. Somewhere within the 40 respondents range, Cronbach's alpha was used to inspect the inside textures of the objects involved in the instrument. These members have been avoided by the actual examination. The analyst knew that there were numerous types of unwavering quality investigation or coefficients, but the Cronbach alpha-reliability test was chosen, which was said to be generally used by most scientists and was considered to be powerful while checking the unwavering quality of the instruments (Coakes and Steed, 2001).

Cronbach alpha estimation ranges from 0 to 1 , where 0 implies zero reliability (lack of internal consistency) while one implies unwavering quality. In any case, getting one was relatively inconceivable, but the closer the estimation of Cronbach's alpha is to one, the more reliable the information. On the basis of this review, 40 thing investigations were set up in the survey to test the factors under investigation.
Since Cronbach's alpha is influenced by the length of the test (when things are extensive Cronbach's alpha tends to be high and when there are fewer things Cronbach's alpha slopes below) the analyst has isolated things in their classifications. After this progress, the analyst ensured that the external components did not interfere with the assessment of the unwavering quality of the survey, with a view to ensuring that its accuracy and consistency were known (Table 2).

\begin{tabular}{|c|c|c|c|c|}
\hline No & Factors & $\begin{array}{c}\text { No. of } \\
\text { Questions }\end{array}$ & $\begin{array}{c}\text { Reliabi } \\
\text { lity }\end{array}$ & comment \\
\hline 1 & Career Risk & 7 & 0.798 & Reliable \\
\hline 2 & $\begin{array}{c}\text { Organizational } \\
\text { Productivity }\end{array}$ & 10 & 0.849 & Reliable \\
\hline
\end{tabular}

The reliability test for all measurements was found to be tasteful, as most analysts have agreed that, in order for any instrument to be robust, it must meet the basic purpose of.70 or more (Hair et al., 2014).

\subsection{Pilot Study Validity}

It is essential to also ascertain the discriminant validity when ensuring the construct validity of the outer model. It is necessary to take this step before testing the hypotheses with the path analysis. Discriminant validity indicates the level of which items distinguish among constructs. In other words, it indicates that there is no overlapping among the items since they use different constructs. Thus, though constructs correlated, they measure different concepts and ideas. Hair et al. (2014) clearly elucidated when discriminant validity of a measure has been ascertained, it indicates that the variance shared between constructs and their measures must be higher than the shared variance among different constructs.

Discriminant validity can be determined in two ways. These ways include first, testing the correlations that exist between the measures of constructs that will possibly overlap, and second, applying the Fornell\&Larcker (1981) method. In regards to this method, each construct AVE must be higher compared with the square of the inter-correlation between two constructs, or each construct AVE square root must be higher compared with the correlation between a specific construct and other available constructs. Based on this, this study used both methods to confirm the measures' discriminant validity. Table 3 shows the validity of the questions in the questionnaire according to the comments of 4 academic and managerial experts. Table 3 show theValidity:

\begin{tabular}{|c|c|c|c|}
\hline No & Factors & No. of Questions & Validity \\
\hline 1 & Career Risk & 7 & $86 \%$ \\
\hline 2 & $\begin{array}{c}\text { Organizational } \\
\text { Productivity }\end{array}$ & 10 & $91 \%$ \\
\hline
\end{tabular}

As shown in Table above 86 and 91 per cent were appropriate to the questionnaire as a result of the consensus perspectives of the four academic experts. The validity of the questionnaires was determined to be $86 \%$ and $91 \%$ 
(satisfactory), and 40 interested participants were asked, after their input, to take part in the pilot study, according to the opinion of five specialists. Based on the pilot analysis, the responses to the reliability of the information were based on mathematical test procedures. The purpose of the study and the research content and purpose were conveyed to the interviewees. Knowledge and measurement reliability was calculated using the alpha values of Cronbach. Churchill (1979) claimed that the measurement of tool efficiency is a key measure of reliability. The most common value of alpha Cronbach is $0.60-0.70$ (Hair et al. 2010).

\subsection{Computations of Effects on Variables}

Table 4 shows the Standardized Total Effects - Two Tailed Significance

\begin{tabular}{|c|c|}
\hline & Career Risk \\
\hline $\begin{array}{c}\text { Organizational } \\
\text { Productivity }\end{array}$ & .719 \\
\hline
\end{tabular}

These are a bootstrap approximation obtained by constructing two-sided bias-corrected confidence intervals. The standardized total (direct and indirect) effect of (CR) on (OP) is not significantly from zero at the 0.05 level ( $\mathrm{p}=.719$ twotailed).

\section{DISCUSSION, CONCLUSION AND RECOMMENDATIONS}

\subsection{Discussions of Findings}

As a preamble, it has been noted from the assertion of a number of studies from this stream of researches, findings reveal that ground-breaking HRM observes, and particular sets of corresponding observes, guide to improvement in employee attitudes towards their career and as such causes a corresponding improvement in increases in plant- and establishment-level productivity outcomes in manufacturing and construction industries. An additional surge of research investigates reactions and responses that workers provide for demeanor or assessment reviews.

Due to this assertion, the current study addresses the research question - Is there an impact of the Career Risk on Organizational Productivity of Construction companies in Libya? This directed to the origination of research hypothesis (H1) which states that there is Career Risk (CR) has a positive significant relationship with Organizational Productivity (OP). The result shows Career Risk (CR) is not significantly at level 0.05 as $\mathrm{p}$ is .719 which is greater than .05 . Therefore, this hypothesis (H3) is not supported

The empirical analysis supports the following assertion of Tatar (2020), Asghari (2019), Romero et al. (2018), Azoulay et al., (2010), Bandiera et al. (2007), and Brondino et al. (2012).

The attitudes of employees towards career risks which can have a substantial effect on the business as a whole in the workplace. Career Risk on Organizational Productivity is a crucial factor, one of the unknown, hard-to-measure factors which have been considered responsible for the accomplishment of an organization. Regardless of whether for better, the patterns of staff frames of mind strongly affect the profitability of businesses, equally legitimately and through the impact on other occupation-related aspects.

\subsection{Conclusion}

The study explains the way in which the specific research objectives were achieved in relation to the previously established results. This study examines the application of health and occupational safety by construction companies in Libya using SEM. This research recommended an increase focus on health and occupational safety in industrial companies.

This study focuses on addressing the applicability of career risk and career commitment, founded in developed countries, to cultures other than Western or developing countries.

The main belief is that all theories of adopting modern health and occupational safety are created and generated in developed countries, causing these theories to suffer from industrial and cultural bias. This bias might stop the applicability of these HRM theories when moving to other cultures and environments. On the contrary, the developments of HRM methods during the last years of the twentieth century have led to the necessity of companies keeping pace with this development at the local and global levels, in addition to their benefits, making it impossible for companies at the global or local levels to ignore these advantages or avoid the application of methods Modern in HRM. Moreover, the current work has enriched the knowledge related to the acceptance of modern methods in HRM within the scientific work of management theories. Also, this study indicates that career risk and career commitment was a successful model in studying health and occupational safety and organizational productivity in Libya.

\subsection{Limitations}

This study had some limitations. These include; single-source bias, as the data collection was done by just personnel in which were employed within construction fields in Libya. The data was gathered due to ease of accessibility to this research population and convenience. Employees from other industrial sectors were not surveyed disregarding the fact that they might have had some intervening factors that might impact their responses hence producing different responses and overall results. Furthermore, another substantial limitation of this study was that required information has been composed and assembled only within a single point within the timedomain (cross-sectional), however, it had been well established that respondent's opinions might differ with time.

\subsection{Recommendations for Future Studies}

The recommendations are directed to other developing countries as well as to future researchers working on the related subject matter. For future researchers, 
recommendations are made in line with carrying further, beyond the limitations encountered during the course of the current study as well as what can be done as the next step to this study. Furthermore, since health and occupational safety was an international notion besides requires to be considered for further investigations throughout a great amount of broader environmental well as researched within the scope of a greater and more comprehensive populace, it is recommended to future researchers to gather data from other research contexts, and to some other industries so that hidden variables can be identified as well as a comparative analysis can be carried out.

\section{REFERENCES}

[1] Asghari, M. (2019). Impact of jasmines on safety, productivity and physiology of food crops. Trends in Food Science \& Technology, 91, 169-183.

[2] Azoulay, P., Joshua, Z. \& Wang, J. (2010). Superstar Extinction, Quarterly Journal of Economics125(2), 549-589.

[3] Babbie, E., \& Rubin, A. (2010). Essential research methods for social work. Belmont, Ca.

[4] Balakrishnan, N. (2007). Progressive censoring methodology: an appraisal. Test, 16(2), 211.

[5] Bandiera, O., Iwan, B, \& Imran, R. (2007). Incentives for Managers and Inequality among Workers: Evidence from a Firm Level Experiment. Quarterly Journal of Economics 122(2), 729773.

[6] Blais, A. R., \& Weber, E. U. (2006). A domain-specific risk-taking (DOSPERT) scale for adult populations.

[7] Brondino, M., Silva, S.A., \&Pasini, M., (2012). Multilevel approach to organizational and group safety climate and safety performance: Co-workers as the missing link. Safety Science 50: 1847-1856.

[8] Bryman, A., \& Bell, E. (2015), Business research methods. Oxford University Press, USA

[9] Cavana, R. Y., Delahaye, B. L., \&Sekaran, U. (2001), Applied business research: Qualitative and quantitative methods. John Wiley \& Sons Australia

[10] Crossan, F. (2003). Research philosophy: towards an understanding. Nurse Researcher (through 2013), 11(1), 46.

[11] Felt, O., Buri, P., \&Gurny, R. (1998). Chitosan: a unique polysaccharide for drug delivery. Drug development and industrial pharmacy, 24(11), 979-993.

[12] Fornell, C., \&Larcker, D. F. (1981). Structural equation models with unobservable variables and measurement error: Algebra and statistics.

[13] Franco, M., \&D'Angelo, N. (2011). Investment Risk Behavior in Different Domains: Entrepreneurs vs. Public Employees

[14] Galliers, R. (1992). Information systems research: Issues, methods and practical guidelines. Blackwell Scientific.

[15] Guba, E. G., \& Lincoln, Y. S. (1994). Competing paradigms in qualitative research. Handbook of qualitative research, 2(163-194), 105.

[16] Hair, J. F. (2010). Multivariate data analysis. Pearson College Division.

[17] Hair, J. F., Black, W. C., Babin, B. J., \& Anderson, R. E. (2014). Multivariate data analysis: Pearson new international edition. Essex: Pearson Education Limited.

[18] Hanoch, Y., Johnson, J. G., \&Wilke, A. (2006). Domain specificity in experimental measures and participant recruitment: An application to risk-taking behavior. Psychological Science, 17(4), 300-304

[19] Hart, S. D. (2001). Assessing and managing violence risk. HCR-20 violence risk management companion guide, 13-25.

[20] Herrero, J., Urueña, A., Torres, A., \& Hidalgo, A. (2016). My computer is infected: the role of users' sensation seeking and domain-specific risk perceptions and risk attitudes on computer harm. Journal of Risk Research, 1-14

[21] Hesse-Biber, S. J., Hesse-Biber, S. N., \&Leavy, P. (Eds.). (2006). Emergent methods in social research. Sage.

[22] Judge TA, Kammeyer-Mueller JD, Weiss HM et al. (2017). Job attitudes, job satisfaction, and job affect: A century of continuity and of change. Journal of Applied Psychology, 102(3): 356-374

[23] Karatepe, O.M. and Avci, T. (2017), "The effects of psychological capital and work engagement on nurses' lateness attitude and turnover intentions", Journal of Management Development, Vol. 36 No. 8, pp. 1029-1039. https://doi.org/10.1108/JMD-07-20160141

[24] Krejcie, R.V and Morgan, D.W (1970). Determining Sample Size for Research Activities. Educational and Psychological Measurement, 30, 607-610.

[25] Lauriola, M., \& Levin, I. P. (2001). Personality traits and risky decision-making in a controlled experimental task: An exploratory study. Personality and Individual Differences, 31(2), 215-226.

[26] Lawrence, T. B., \&Suddaby, R. (2006). 1.6 institutions and institutional work. The Sage handbook of organization studies, 215-254.

[27] Leedy, P. D., \&Ormrod, J. E. (2005). Practical research. Pearson Custom.

[28] Mearns, K., Flin, R., Gordon, R., \& Fleming, M. (2001). Human and organizational factors in offshore safety. Work \& Stress, 15, $144-160$.

[29] Mertens, D. M. (2008). Transformative research and evaluation. Guilford press.

[30] Mishra, S., \&Lalumière, M. L. (2011). Individual differences in risk-propensity: Associations between personality and behavioral measures of risk. Personality and Individual Differences, 50(6), 869-873

[31] Myers-Scotton, C. (1997). Dueling languages: Grammatical structure in codeswitching. Oxford University Press.

[32] Nduro, M. (2012). The effect of motivation on the performance of employees at GT bank Ghana (Doctoral dissertation).

[33] Nicholson, N., Soane, E., Fenton-O'Creevy, M., \&Willman, P. (2005). Personality and domain-specific risk taking. Journal of Risk Research, 8(2), 157-176

[34] Okoye, P. V. C., \&Ezejiofor, R. A. (2013). The effect of human resources development on organizational productivity. International Journal of Academic Research in Business and Social Sciences, 3(10), 250.

[35] Olu\&Majekodunmi (2020). Climate change impact on workers' health, safety and productivity. Climate Change, 2020, 6(21), 156167

[36] Phipps, S. T., Prieto, L. C., \&Ndinguri, E. N. (2013). Understanding the impact of employee involvement on organizational productivity: The moderating role of organizational commitment. Journal of Organizational Culture, Communications and Conflict, 17(2), 107

[37] Pinsonneault, A., \& Kraemer, K. (1993). Survey research methodology in management information systems: an assessment. Journal of management information systems, 10(2), 75-105.

[38] Romero, D., Mattsson, S., Fast-Berglund, Å.,Wuest, T., Gorecky, D., \&Stahre, J. (2018). Digitalizing occupational health, safety and productivity for the operator 4.0. In IFIP International Conference on Advances in Production Management Systems (pp. 473-481). Springer, Cham.

[39] Saunders, M., Philip, L., \& Adrian, T., (2009). Research Methods for Business Students. 5th ed. Edinburgh: Ess: Pearson Education Ltd. 61.

[40] Sekaran, U. (2003). Research Methods for Business - A Skill Building Approach. Carbondale, IL: John Wiley \& Sons, Inc., p. 63.

[41] Sekaran, U., \&Bougie, R. (2003). Research method of business: A skill Building Approach. New York: John Willey \& Sons.

[42] Tatar, Ali. (2020). Impact of Job Satisfaction on Organizational Commitment. 
[43] Tchapchet, E. T. (2013). The impact of employee participation on organisational productivity at a university of technology in the Western Cape, South Africa (Doctoral dissertation, Cape Peninsula University of Technology).

[44] Wearing, S., \& Neil, J. (2009). Ecotourism: Impacts, potentials and possibilities? Routledge.

[45] Weber, E. U., Blais, A. R., \& Betz, N. E. (2002). A domain-specific risk-attitude scale: Measuring risk perceptions and risk behaviors. Journal of behavioral decision making, 15(4), 263290

[46] Zeng, D., \& Lin, D. Y. (2007). Maximum likelihood estimation in semiparametric regression models with censored data. Journal of the Royal Statistical Society: Series B (Statistical Methodology), 69(4), 507-564. 